\title{
Daily physical activity counts vs structured activity counts in lean and overweight Dutch children.
}

Citation for published version (APA):

Vogels, N., Westerterp, K. R., Posthumus, D. L., Rutters, F., \& Westerterp-Plantenga, M. S. (2007). Daily physical activity counts vs structured activity counts in lean and overweight Dutch children. Physiology \& Behavior, 92(4), 611-616. https://doi.org/10.1016/j.physbeh.2007.05.007

Document status and date:

Published: 01/01/2007

DOI:

10.1016/j.physbeh.2007.05.007

Document Version:

Publisher's PDF, also known as Version of record

Document license:

Taverne

Please check the document version of this publication:

- A submitted manuscript is the version of the article upon submission and before peer-review. There can be important differences between the submitted version and the official published version of record.

People interested in the research are advised to contact the author for the final version of the publication, or visit the DOI to the publisher's website.

- The final author version and the galley proof are versions of the publication after peer review.

- The final published version features the final layout of the paper including the volume, issue and page numbers.

Link to publication

\footnotetext{
General rights rights.

- You may freely distribute the URL identifying the publication in the public portal. please follow below link for the End User Agreement:

www.umlib.nl/taverne-license

Take down policy

If you believe that this document breaches copyright please contact us at:

repository@maastrichtuniversity.nl

providing details and we will investigate your claim.
}

Copyright and moral rights for the publications made accessible in the public portal are retained by the authors and/or other copyright owners and it is a condition of accessing publications that users recognise and abide by the legal requirements associated with these

- Users may download and print one copy of any publication from the public portal for the purpose of private study or research.

- You may not further distribute the material or use it for any profit-making activity or commercial gain

If the publication is distributed under the terms of Article $25 \mathrm{fa}$ of the Dutch Copyright Act, indicated by the "Taverne" license above, 


\title{
Daily physical activity counts vs structured activity counts in lean and overweight Dutch children
}

\author{
N. Vogels, K.R. Westerterp, D.L.A. Posthumus, F. Rutters, M.S. Westerterp-Plantenga* \\ Department of Human Biology, Maastricht University, P.O. Box 616, 6200 MD Maastricht, The Netherlands
}

Received 3 January 2007; received in revised form 23 April 2007; accepted 2 May 2007

\begin{abstract}
The objectives of this study were to compare daily physical activities, and activities performed according to a structured protocol, measured with tri-axial accelerometers (Tracmor-4), between lean and overweight children. Fourteen overweight children (59.8 $\pm 9.5 \mathrm{~kg})$ and fifteen lean matched controls $(47.2 \pm 8.7 \mathrm{~kg})$ wore the Tracmor- 4 daily, during $12 \pm 1.3 \mathrm{~h}$, for one week in their home environment. Of these, 24 children participated in a sports afternoon, where they performed activities according to the same structured protocol. In addition, physical activity was estimated using a modified Baecke questionnaire. Body composition was determined. Total mean Tracmor counts/day were significantly lower for the overweight children than for the lean (overweight: $46.1 \pm 6.9$ vs. lean: $54.4 \pm 11.2 \mathrm{kCounts} /$ day, $p=0.02$ ), while reported activities (Baecke score) were similar. When performing activities according to the structured protocol, there was no difference in mean Tracmor counts between the two groups (overweight: $36.3 \pm 6.9$ vs. lean: $34.7 \pm 6.6 \mathrm{kCounts}, p=0.6$ ). Daily physical activities were inversely related to percentage body fat $\left(r^{2}=0.29, p<0.01\right)$; structured activities were not. As compared to lean children, overweight children moved less without being aware of it; yet exerted the same movements per activity. We conclude that in overweight children daily physical activities were reduced and structured activities performed according to instructions were not. In order to prevent progressive overweight or obesity, overweight children should take part in as many as possible structured and scheduled sports activities throughout the week, and be encouraged to behave physically active in daily life.
\end{abstract}

(C) 2007 Elsevier Inc. All rights reserved.

Keywords: Tri-axial accelerometry; Children; Obesity; Baecke questionnaire

\section{Introduction}

The prevalence of childhood obesity is emerging as a major health problem $[1,2]$. It is associated with several risk factors for later heart disease and other chronic diseases [3,4]. Energy expenditure, like energy intake, is an important factor in the development of obesity [5,6]. Already in 1956, Mayer, Roy and Mitra [7] published a study on relations between caloric intake, body weight and physical work. This investigation purported to show that the groups of employees who were relatively sedentary (13 stallholders, 8 supervisors and 22 clerks) had on average

\footnotetext{
* Corresponding author. Tel.: +31 43 3881566; fax: +31 433670976 .

E-mail address: M.Westerterp@HB.Unimaas.nl (M.S. Westerterp-Plantenga).
}

a higher energy intake and a higher body weight than employees who were engaged in light physical work [7]. Compared to adolescents [8] or adults, children move relatively much, however, physical activity in this young group seems to decrease over the past several decades, especially in the USA [9]. Different studies estimating the effect of physical activity in childhood, usually by questionnaire, find different effects of activity in relation to overweight or obesity [10]. One reason for this uncertainty is discrepancy in the accuracy of physical activity measurement techniques used. In recent years, the measurement of physical activity with accelerometers has become more widely used. These instruments provide minute-by-minute quantification of body movement over periods of several days or even weeks, enabling patterns of movement or inactivity to be assessed. The Tracmor-4, a tri-axial accelerometer, has been validated against energy expenditure measured by the doubly 
labelled water method; it was proven to be a reliable tool for assessment of physical activity [11]. The main conclusion from previous studies [12-16] is that physical activities, expressed as activity counts, representing numbers and sizes of movements, were reduced in obese adolescents [15], yet given the performance regarding weight bearing activities that they undertake, their activity induced energy expenditure is not reduced compared to their lean counterparts. To follow this up, we assessed whether only possible differences in physical activity counts representing numbers and sizes of movements in daily life are reduced, or whether also during identically structured and instructed sports activities a difference in performing these activities would appear, for instance in how vigorously the movements would be performed. Overweight children may for example move less intensively or take more small breaks when performing similar activities. The main research question was: do possible differences in physical activity between overweight and normal weight children relate to physical activity under habitual daily life conditions or to physical activity expressed during structured sports activities?

\section{Methods}

\subsection{Study design}

Subjects were recruited from a Dutch Caucasian birth-cohort of children born between 1990 and 1993 [17,18]. As infants, these children and their mothers participated in i) a study of essential fatty acids during pregnancy and pregnancy outcome [16], and ii) a study, performed between 1997 and 2000, about the long-term effects of fetal essential fatty acid availability [18]. Anthropometric data were available from these children. No interventions were carried out. To evaluate the development of overweight and related parameters, a follow-up study was performed in 2004 [19]. In this whole group of 105 children, 16 children were overweight. These 16 overweight children and 16 matched (for age, height and gender) controls from the same cohort were asked to wear a tri-axial accelerometer (Tracmor-4) for one week. Two overweight children and one lean child refused. In total, 29 children (14 overweight/15 lean) wore the Tracmor for 7 consecutive days (Table 1). Also, their activity counts were measured during an organized sports afternoon (Table 1), where the children $(n=24)$ performed activities according to exactly the same activity protocol. In addition, measurements of children's reported activity score (Baecke questionnaire) and body composition were executed.

Each child and one of his or her parents gave written informed consent to participate in the study, which was approved by the CCMO (Central Committee Human Research in The Hague) and by the Medical Ethical Committee of the Maastricht University Hospital.

\subsection{Measurements}

\subsubsection{Physical activity}

Physical activity can easily be estimated with the Baecke questionnaire. The Baecke questionnaire consists of three
Table 1

Subject characteristics of 15 lean and 14 overweight children

\begin{tabular}{|c|c|c|c|c|}
\hline \multirow[t]{3}{*}{ Gender (m/f) } & \multicolumn{2}{|l|}{ Lean } & \multicolumn{2}{|c|}{ Overweight } \\
\hline & Mean & SD & Mean & $\mathrm{SD}$ \\
\hline & \multicolumn{2}{|l|}{$8 / 7$} & \multicolumn{2}{|l|}{$7 / 7$} \\
\hline Age (y) & 12.1 & 1.1 & 12.0 & 1.2 \\
\hline Height $(\mathrm{cm})$ & 160.7 & 10.2 & 159.5 & 9.4 \\
\hline Body weight $(\mathrm{kg})^{\mathrm{a}}$ & 47.2 & 8.7 & 59.8 & 9.5 \\
\hline Waist circumference $(\mathrm{cm})^{\mathrm{a}}$ & 64.3 & 5.2 & 75.4 & 3.9 \\
\hline BMI $\left(\mathrm{kg} / \mathrm{m}^{2}\right)^{\mathrm{a}}$ & 18.1 & 1.5 & 23.3 & 2.1 \\
\hline Body fat $(\%)^{\mathrm{a}}$ & 17.2 & 5.4 & 31.4 & 5.1 \\
\hline Fat mass $(\mathrm{kg})^{\text {a }}$ & 8.0 & 2.6 & 18.7 & 3.3 \\
\hline Fat free mass $(\mathrm{kg})$ & 39.2 & 8.3 & 41.5 & 8.5 \\
\hline Physical activity (Baecke total) & 8.4 & 0.6 & 8.1 & 1.4 \\
\hline Baecke school & 2.5 & 0.3 & 2.5 & 0.3 \\
\hline Baecke sports & 3.1 & 0.4 & 2.8 & 0.9 \\
\hline Baecke leisure & 2.8 & 0.3 & 2.8 & 0.5 \\
\hline $\begin{array}{l}\text { Physical activity } \\
{\text { (kCounts/day })^{\mathrm{a}, \mathrm{b}}}^{\text {(k) }}\end{array}$ & 54.4 & 11.2 & 46.1 & 6.9 \\
\hline 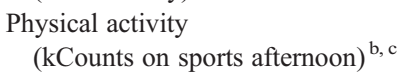 & 34.7 & 6.6 & 36.3 & 6.9 \\
\hline
\end{tabular}

components: work activity, sports activity and leisure activity $[20,21]$ and has been validated using doubly labelled water [22]. For the children, the work index was replaced by a school index with similar questions (e.g. "When I am in school, I walk.. "never/seldom/sometimes/often/all the time?").

To measure physical activity more accurately, daily movements were assessed with a tri-axial accelerometer for movement registration (Tracmor, Philips Research, Eindhoven, The Netherlands). In children, in a wide weight range including overweight children, the Tracmor has been validated against doubly labelled water by Hoos et al. $[23,24]$. The Tracmor-4 contains three uni-axial piezo-electric accelerometers, measures $7.2 \times 2.6 \times 0.7 \mathrm{~cm}$, and weighs $22 \mathrm{~g}$ (battery included) [11]. It is attached to the lower back by means of an elastic belt, measuring accelerations in the antero-posterior, medio-lateral and longitudinal axis of the trunk. The Tracmor provides minute-byminute data for all three axes separately, which are then integrated. For this study, Tracmor output was defined as integrated activity counts per day (for the sum of all three axes), which is the sum of all counts over 7 days divided by 7 . Subjects were instructed to wear the Tracmor for 7 consecutive days, during waking hours, except while showering or swimming. The parents of the children recorded times in a log when the children woke up, when the Tracmor was put on and taken off, and when the children went to bed. According to the protocol, the difference between sleeping time $(9.9 \pm 0.9 \mathrm{~h})$ and hours of wearing the Tracmor $(12 \pm 1.3 \mathrm{~h})$ was $2 \mathrm{~h}$ per child.

A sports afternoon was organized, where 24 children (13 lean and 11 overweight) participated, and again wore the Tracmor. At the gym, they were instructed to perform activities according to a same structured protocol. Activities included walking, running, stretching, street dance, and different ball games. All activities were guided by two sports instructors. 


\subsubsection{Anthropometry}

The children's height was measured using a wall-mounted stadiometer accurate to $0.1 \mathrm{~cm}$ (Seca, model 220, Hamburg, Germany) and body weight (BW) was measured using a digital balance accurate to $0.1 \mathrm{~kg}$ (Sauter D7470, Ebingen, Germany). Measurements were executed in underwear, after an overnight fast and after voiding. BMI was calculated as BW/height ${ }^{2}$ $\left(\mathrm{kg} / \mathrm{m}^{2}\right)$. BMI in childhood changes substantially with age. To define normal, overweight and obesity in children, we used the age and sex specific cut off points described by Cole et al. [4]. The waist circumference was measured at the site of the smallest circumference between the rib cage and the ileac crest, with the subjects in standing position.

\subsubsection{Body composition}

Body composition was measured using the deuterium dilution technique. ${ }^{2} \mathrm{H}_{2} \mathrm{O}$ dilution was used to measure total body water (TBW). Subjects were asked to collect a urine sample in the evening just before drinking the deuteriumenriched water solution. After ingestion of this solution, no further consumption was allowed. Ten hours after drinking the water solution, another urine sample was collected. The dilution of the deuterium isotope is a measure of the TBW of the subject. Deuterium was measured in the urine samples with an isotope ratio mass spectrometer (Optima, VG Isogas, Middlewich, Cheshire, England). TBW was obtained by dividing the measured deuterium dilution space by 1.04 . Fat free mass (FFM) was calculated by dividing TBW by the hydration factor 0.73 [25-27]. Fat mass (FM) was determined as BW-FFM.

\subsection{Data analysis}

Tracmor output was defined as integrated activity counts per day (for the sum of all three axes), which is the sum of all counts over 7 days divided by 7 . This was done individually for wearing hours/day $(12 \pm 1.3 \mathrm{~h} / \mathrm{d}$, which is $24 \mathrm{~h}$ minus $2 \mathrm{~h}$ preparations, minus sleeping time: $9.9 \pm 0.9 \mathrm{~h} / \mathrm{d}$ ). For the sport afternoon, Tracmor output was defined as total activity counts, which is the sum of all counts registered on that afternoon. First of all, the relationship between the Baecke scores and Tracmor output in children was compared to the validation for adults by Philippaerts et al. [28]. Similar to the observed relationship in adults $(r=0.37(p<0.001))$, we found a correlation of the total mean Tracmor counts and the Baecke sports index of $r=0.37$ $(p<0.05)$. Daily physical activity in counts per day as well as in Baecke scores was compared between lean and overweight children using an independent $t$-test. An independent $t$-test was also used to compare the Tracmor total counts on the sports afternoon between the lean and overweight children. With a two-factor ANOVA repeated measures analysis it was assessed whether the difference in daily counts and structured counts was different between overweight and normal weight children. Daily physical activity counts as well as structured physical activity counts was also expressed as a function of percentage body fat. For all statistics Statview SE Graphics ${ }^{\mathrm{TM}}$ for Macintosh was used. All statistical tests were two-sided and differences were considered significant at $p<0.05$. Values are expressed as mean \pm standard deviation (SD).

\section{Results}

Obviously, overweight children had a significantly higher BW, BMI, waist circumference, $\%$ body fat and fat mass than the lean children. The children showed good compliance with wearing the Tracmor. All of them kept the protocol of wearing the Tracmor from $1 \mathrm{~h}$ after getting up until $1 \mathrm{~h}$ before being in bed again. Mean duration of wearing was $12.1 \pm 1.2 \mathrm{~h}$ per day in lean children and $11.9 \pm 1.4 \mathrm{~h}$ per day in overweight children. This did not differ significantly between the lean and overweight children $(p=0.84)$.

Overweight children had a significantly lower Tracmor registration ( $46.1 \pm 6.9$ vs. $54.4 \pm 11.2 \mathrm{kCounts} / \mathrm{day}, p=0.02)$, while the reported physical activities (score on Baecke questionnaire) were not statistically different (Table 1). During the organized sports afternoon, when all activities were performed according to the same structured protocol, during exactly the same period of time, there was no difference in Tracmor registration between the overweight and the lean children (overweight: $36.3 \pm 6.9$ vs. lean: $34.7 \pm 6.6 \mathrm{kCounts}, p=0.6$ ). The difference between activity counts during average daily life and during the sports afternoon was different between the normal weight and overweight children $(p<0.05)$. For normal weight children this difference was considerable $(p<0.0001)$, for the overweight children it was also present, yet less pronounced $(p<0.01)$. Fig. 1 shows the individual values of activity counts during daily life as well as during the sports afternoon, both as a function of percentage body fat. It shows a significant inverse relationship between daily physical activities and percentage body fat, yet not for structured activities and percentage body fat. Here it is also

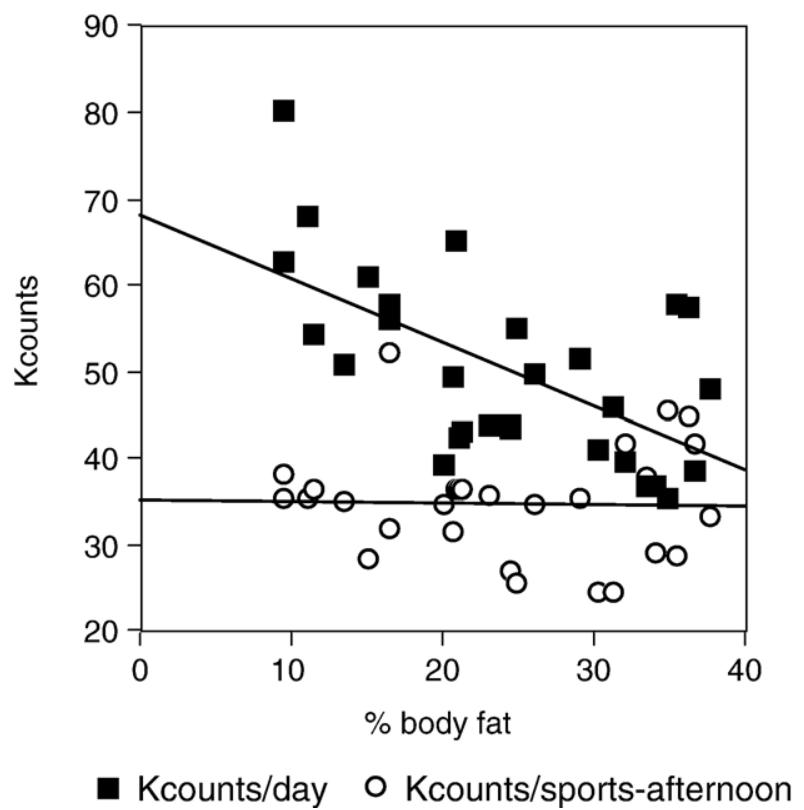

Fig. 1. kCounts physical activities/day during daily life as a function of \% body fat in 29 normal weight and overweight children, ages 12.1 \pm 1.1 yrs (black squares); $r^{2}=0.29 ; p<0.01$. kCounts of \% body fat (open circles) (ns). 
illustrated that in normal weight children the level of physical activities during their daily life is considerably higher than the level of the structured sports activities on one day, while for overweight children the physical activities during the sports afternoon represent most of the activities they perform during an average day.

There was no gender effect on physical activity counts, neither in the overweight nor in the normal weight population. In daily life these figures were: overweight: men: $47.4 \pm 5.1 \mathrm{kCounts}$; women $44.7 \pm 5.2$ kCounts (ns); normal weight: men: $59.4 \pm$ 6.2 kCounts; women: $48.6 \pm 7.1$ kCounts (ns). During the sports afternoon these figures were: overweight: men $39.4 \pm 5.3 \mathrm{kCounts}$; women: $32.4 \pm 4.7 \mathrm{kCounts}(\mathrm{ns})$; normal weight: men: $36.2 \pm$ 4.9 kCounts; women: $32.8 \pm 4.5$ kCounts (ns).

\section{Discussion}

This study confirms that overweight children have lower free-living activity counts than lean children. On the other hand, their reported activities were not statistically different. When performing activities according to the same structured protocol, there was no difference in accelerometer output (kCounts), which shows that the movements of overweight children during specific activities were similar to lean children.

When the children were in their typical living environment, where they were free to move as much or as little as they liked, and were free to choose their own types of activities, overweight children moved significantly less than their lean counterparts. This cannot be due to differences in sleeping time or in hours of wearing the Tracmor, since there were no statistically significant differences in sleeping time or wearing hours.

The famous study by Mayer et al. [7], published in 1956, serves as the historical background of this research. The topic was on relations between caloric intake, body weight and physical work. The groups of employees who were relatively sedentary (13 stallholders, 8 supervisors and 22 clerks) had on average a higher energy intake and a higher body weight than employees who were engaged in light physical work, leading to the suggestion that there may be a relationship between physical activity and obesity. Yet the group this comparison was executed with, was not completely matched. On examining the data it can be seen that the clerks who were sedentary had a higher food intake but a lower body weight than the 28 clerks who were assigned to 'light' work [29]: so this observation may not support a possible relationship between physical activity and the development of obesity.

The present study is limited by its cross-sectional design, so conclusions as to whether an inactive lifestyle causes obesity or whether obesity leads to an inactive lifestyle cannot be drawn. However, it clearly shows differences in physical activity between overweight and lean children. These findings are consistent with other data in children and adolescents [12-16]. Furthermore, this study shows that there was no difference in reported physical activity (as measured with the Baecke questionnaire) between both groups, which indicates that the overweight children in fact overestimated their activities. Similar to underreporting food intake [30-32], physical activity is generally overreported, especially in the overweight [33], which offers an explanation of the overestimated physical activity in the overweight children. This also explains the limited though significant explained variation in the Baecke scores by the Tracmor counts.

Guided by two sports instructors during an organized sports afternoon, the overweight and lean children performed activities according to the same structured protocol. Here, the results showed that the Tracmor movement registration (kCounts) of the overweight and lean children was not statistically different. This implicates that only in free-living daily circumstances, when children are free to choose and perform their own preferred activities, there was a significant difference in physical activity counts between overweight and lean children. The fact that overweight children moved less in these circumstances, in terms of activity counts as measured by accelerometers, does not necessarily mean that their energy expenditure is also lower. Basal metabolic rate (BMR), total energy expenditure (TEE), activity-related energy expenditure $(\mathrm{AEE}=\mathrm{TEE}-\mathrm{BMR})$ or physical activity level $(\mathrm{PAL}=\mathrm{TEE} / \mathrm{BMR})$ have frequently been reported to be the same between overweight and lean children $[15,34-36]$. This can be explained by the increased energy cost of moving a larger body mass, by a difference in body acceleration (i.e. activity counts), by a difference in movement economy, or by a combination of these factors [15]. Also, the calculation of activity induced energy expenditure (AEE) from Tracmor counts consists of a formula that takes anthropometry details into account, i.e. $\mathrm{PAL}=a *$ average Tracmor counts/day $+b(r=0.79, p<0.01$ for regression PAL and Tracmor counts) [22]. Since PAL is defined as TEE/BMR, and TEE $=\mathrm{BMR}+\mathrm{AEE}+\mathrm{DIT}$ (diet induced thermogenesis), and since BMR is determined by body mass, the equation shows that for the same PAL, overweight children need more AEE than lean children [23].

Recently, Page et al. (2005) performed a comprehensive study in which they looked at physical activity patterns in children [12]. They found that 25 obese children were significantly less physically active than their 108 non-obese counterparts. Physical activity was measured with CSA accelerometers during waking hours when carrying out their normal daily activities for seven days. Comparing our results to the results of Page et al., both reported that overweight children indeed move less than lean children. In addition, from our study we can conclude that it is truly the initiative to move instead of the intensity of moving, that is lower in the overweight children. Page et al. (2005) measured a large sample of children. The present study measured a relatively small group of children, but with the use of the tri-axial Tracmor-4, which measures daily physical activity more accurately than the uni-axial CSA's [11], we were able to show significant differences even with a small number of subjects. Both studies show, that only firm conclusions on physical activity can be drawn from measured physical activities, by accelerometers validated against energy expenditure.

Taken together, firstly we confirm that, in their typical living environment, overweight children move significantly less than lean children, while at the same time they overestimated their 
activities. The new aspect of this study however is that when performing activities in accordance with exactly the same activity protocol, there was no difference in Tracmor output between overweight and lean children, which shows that the movements during specific activities were similar. This implicates that once children are overweight, they still can perform structured sports activities as well as their lean counterparts. It is the reduced spontaneous physical activities that may contribute to or even promote their overweight status. Therefore, in order to prevent progressive overweight or obesity, overweight children should be offered to take part in as many different structured and scheduled sports activities throughout the week, e.g. school-gym, socker, field-hockey, swimming, and athletics, as well as being encouraged to behave more actively in daily life. Since it is a Dutch population, the policy that could be derived from this is facilitating and promoting the school-gym and school swimming lessons again that have been under debate recently. Furthermore, infrastructure, such as sidewalks is present, and bikes are abundantly available, so these aspects do not need further encouragement.

\section{Acknowledgements}

We thank our subjects for their participation in this study. We gratefully thank Loek Wouters, Jeroen Wijckmans, Marcel den Hoed and Dr. Annemiek Joosen for their assistance, and we acknowledge Dr. Kathleen Melanson for editing the English text. The study was supported by Maastricht University. The authors had no conflict of interest.

\section{References}

[1] WHO. Obesity: preventing and managing the global epidemic. Report of a WHO consultation. World. Health. Organ Technol Rep Ser 2000;894(i-xii): $1-253$.

[2] Livingstone B. Epidemiology of childhood obesity in Europe. Eur J Pediatr 2000;159(1):S14-34.

[3] Berenson GS, Srinivasan SR, Bao W, Newman WP, Tracy RE, Wattigney WA. Association between multiple cardiovascular risk factors and atherosclerosis in children and young adults. The Bogalusa Heart Study. N Engl J Med 1998;338:1650-6.

[4] Cole TJ, Bellizzi MC, Flegal KM, Dietz WH. Establishing a standard definition for child overweight and obesity worldwide: international survey. Br Med J 2000;320:1240-3.

[5] Brownson RC, Boehmer TK, Luke DA. Declining rates of physical activity in the United States: what are the contributors? Annu Rev Public Health 2005;26:421-43.

[6] Williamson DF, Madans J, Anda RF, Kleinman JC, Kahn HS, Byers T. Recreational physical activity and ten-year weight change in a US national cohort. Int J Obes Relat Metab Disord 1993;17:279-86.

[7] Mayer J, Roy P, Mitra KP. Relation between calric intake, body weight and physical work. Am J Clin Nutr 1956;4:169-75.

[8] Ekelund U, Yngve A, Brag S, Westerterp K, Sjostrom M. Body movement and physical activity energy expenditure in children and adolescents: how to adjust for differences in body size and age. Am J Clin Nutr 2004;79: 851-6.

[9] Luepker RV. How physically active are American children and what can we do about it? Int J Obes Relat Metab Disord 1999;23(Suppl 2):S12-7.

[10] Parsons TJ, Power C, Logan S, Summerbell CD. Childhood predictors of adult obesity: a systematic review. Int J Obes Relat Metab Disord 1999;23 (Suppl 8):S1-S107.
[11] Plasqui G, Joosen AM, Kester AD, Goris AH, Westerterp KR. Measuring free-living energy expenditure and physical activity with triaxial accelerometry. Obes Res 2005;13:1363-9.

[12] Page A, Cooper AR, Stamatakis E, Foster LJ, Crowne EC, Sabin M, et al. Physical activity patterns in nonobese and obese children assessed using minute-by-minute accelerometry. Int $\mathrm{J}$ Obes Relat Metab Disord 2005;29:1070-6.

[13] Abbott RA, Davies PS. Habitual physical activity and physical activity intensity: their relation to body composition in 5.0-10.5-y-old children. Eur J Clin Nutr 2004;58:285-91.

[14] Trost SG, Sirard JR, Dowda M, Pfeiffer KA, Pate RR. Physical activity in overweight and nonoverweight preschool children. Int J Obes Relat Metab Disord 2003;27:834-9.

[15] Ekelund U, Aman J, Yngve A, Renman C, Westerterp K, Sjostrom M. Physical activity but not energy expenditure is reduced in obese adolescents: a case-control study. Am J Clin Nutr 2002;76:935-41.

[16] Trost SG, Kerr LM, Ward DS, Pate RR. Physical activity and determinants of physical activity in obese and non-obese children. Int J Obes Relat Metab Disord 2001;25:822-9.

[17] Rump P, Mensink RP, Kester AD, Hornstra G. Essential fatty acid composition of plasma phospholipids and birth weight: a study in term neonates. Am J Clin Nutr 2001;73:797-806.

[18] Rump P, Popp-Snijders C, Heine RJ, Hornstra G. Components of the insulin resistance syndrome in seven-year-old children: relations with birth weight and the polyunsaturated fatty acid content of umbilical cord plasma phospholipids. Diabetologia 2002;45:349-55.

[19] Vogels N, Posthumus DL, Mariman EC, Bouwman F, Kester AD, Rump P, et al. Determinants of overweight in a Dutch children cohort. Am J Clin Nutr 2006;84(4):717-24.

[20] Baecke JA, Burema J, Frijters JE. A short questionnaire for the measurement of habitual physical activity in epidemiological studies. Am J Clin Nutr 1982;36:936-42.

[21] Jacobs DR, Ainsworth BE, Hartman TJ, Leon AS. A simultaneous evaluation of 10 commonly used physical activity questionnaires. Med Sci Sports Exerc 1993;25:81-91.

[22] Philippaerts RM, Westerterp KR, Lefevre J. Doubly labelled water validation of three physical activity questionnaires. Int J Sports Med 1999;20: 284-9.

[23] Hoos MB, Plasqui G, Gerver WJ, Westerterp KR. Physical activity level measured by doubly labeled water and accelerometry in children. Eur J Appl Physiol Occup Physiol 2003;89:624-6.

[24] Hoos MB, Kuipers H, Gerver WJ, Westerterp KR. Physical activity pattern of children assessed by triaxial accelerometry. Eur J Clin Nutr 2004;58: $1425-8$.

[25] van Marken Lichtenbelt WD, Westerterp KR, Wouters L. Deuterium dilution as a method for determining total body water: effect of test protocol and sampling time. Br J Nutr 1994;72:491-7.

[26] Schoeller DA, van Santen E, Peterson DW, Dietz W, Jaspan J, Klein PD. Total body water measurement in humans with $18 \mathrm{O}$ and $2 \mathrm{H}$ labeled water. Am J Clin Nutr 1980;33:2686-93.

[27] Westerterp KR, Wouters L, van Marken Lichtenbelt WD. The Maastricht protocol for the measurement of body composition and energy expenditure with labeled water. Obes Res 1995;3(Suppl 1):49-57.

[28] Philippaerts RM, Westerterp KR, Lefevre J. Comparison of two questionnaires with a tri-axial accelerometer to assess physical activity patterns. Int J Sports Med 2001;22:34-9.

[29] Garrow JS. Effects of exercise on obesiy. Acta Med Scand Suppl 1988;711: $67-73$.

[30] Goris AH, Westerterp-Plantenga MS, Westerterp KR. Undereating and underrecording of habitual food intake in obese men: selective underreporting of fat intake. Am J Clin Nutr 2000;71:130-4.

[31] Schoeller DA, Seidell JC. How accurate is self-reported dietary energy intake? Nutr Rev 1990;48:373-9.

[32] Lissner L, Heitmann BL, Lindroos AK. Measuring intake in free-living human subjects: a question of bias. Proc Nutr Soc 1998;57:333-9.

[33] Rzewnicki R, Vanden Auweele Y, De Bourdeaudhuij I. Addressing overreporting on the International Physical Activity Questionnaire (IPAQ) telephone survey with a population sample. Public Health Nutr 2003;6: 299-305. 
[34] Bandini LG, Schoeller DA, Dietz WH. Energy expenditure in obese and nonobese adolescents. Pediatr Res 1990;27:198-203.

[35] DeLany JP, Harsha DW, Kime JC, Kumler J, Melancon L, Bray GA. Energy expenditure in lean and obese prepubertal children. Obes Res 1995;3(Suppl 1):67-72.
[36] Treuth MS, Figueroa-Colon R, Hunter GR, Weinsier RL, Butte NF, Goran MI. Energy expenditure and physical fitness in overweight vs nonoverweight prepubertal girls. Int J Obes Relat Metab Disord 1998;22: $440-7$. 